\title{
Reduction of Smoke-Generation Ability of Construction Timber
}

\author{
Elena Pokrovskaya ${ }^{1}$ and Feodor Portnov $^{1 *}$ \\ ${ }^{1}$ Moscow State University of Civil Engineering, Department of Integrated Safety in Civil \\ Engineering, 129337, 26, Yaroslavskoye Shosse, Moscow, Russia
}

\begin{abstract}
The problem of reduction of smoke-generation ability for construction timber is of high importance as the smokes and toxic combustion products generating in the course of these materials burning are one of the most dangerous fire factors which threaten life and health of people. According to data presented by Ministry of Emergency Situations of the Russian Federation, rate of mortality due to smoke and toxic combustion gases is more than $70 \%$ of total number of people deaths in fires. In this paper, influence of phosphorus-containing modifiers to smoke-generation ability of timber, and also dependence of smokegeneration ability on chemical reactivity of the modifier in interaction with timber has been studied. The problem on fumigation at construction timber burning can be solved by development of chemical compositions efficiently reacting with the surface layer of the timber so that diffusion of solid carbonaceous particles from the timber surface into atmosphere decreases.
\end{abstract}

The problem of reduction of smoke-generation ability for construction timber is of high importance [1-5] as the smokes and toxic combustion products generating in the course of these materials burning are one of the most dangerous fire factors which threaten life and health of people. Thermal decomposition of timber materials is followed by emission of volatile substances and solid particles. In the atmosphere, solids form smoke aerosol, and the most intense solids emission from the timber surface is observed at glowing [5-8]. At timber materials combustion and at other fire loading, fumigation of evacuation passages causes people disorientation, and also poisoning with fire toxic thermal decomposition products [9-11]. At the moment, solution of problem on fumigation of evacuation passages comes down to the use of automatic smoke removal systems, and the issues of reduction of smoke-generation ability for construction materials is poorly understood. According to data presented by Ministry of Emergency Situations of the Russian Federation, rate of mortality due to smoke and toxic combustion gases is more than $70 \%$ of total number of people deaths in fires. In this regard decrease in smoke-generating ability of construction timber is an important factor of people death risk decrease in the fire. Also, it is important to study these issues in the frame of complex reduction of fire-dangerous properties of timber. Efficient fire retardants for construction timber are structures on the basis of organicphosphorous compositions [12-18].

\footnotetext{
* Corresponding author: romeo-aleks@yandex.ru
} 
In this paper, influence of phosphorus-containing modifiers to smoke-generation ability of timber, and also dependence of smoke-generation ability on chemical reactivity of the modifier in interaction with timber has been studied.

Pine sapwood timber modified with 20\%-solutions of following phosphorus compositions was studied: dimethylphosphite (DMF), diethylphosphite (DEF), dipropylphosphite (DPF), dibutylphosphite (DBF), diphenylphosphite (DFF), ammonia polyphosphate (PFA). Water (for DEF, DMF and PFA-1) and acetone (for other compositions) were used as solvents. Use of obtained composition is $300 \mathrm{~g} / \mathrm{m}^{2}$.

Tests of smoke-generation ability for fire-protected timber were carried out by a reference technique, in accordance with Interstate Standard 12.1.044-89 for glowing state, at heat flow of $5-35 \mathrm{~kW} / \mathrm{m}^{2}$.

As a result (Figure 1), the following is observed: smoke-generation ability of timber in the presence of ethers of phosphorous acid are decreased by 5 times in case of use of diethylphosphite and by 1.5 - 2 times for other ethers of phosphorous acid. These results demonstrate high smoke reduction ability of diethylphosphite.

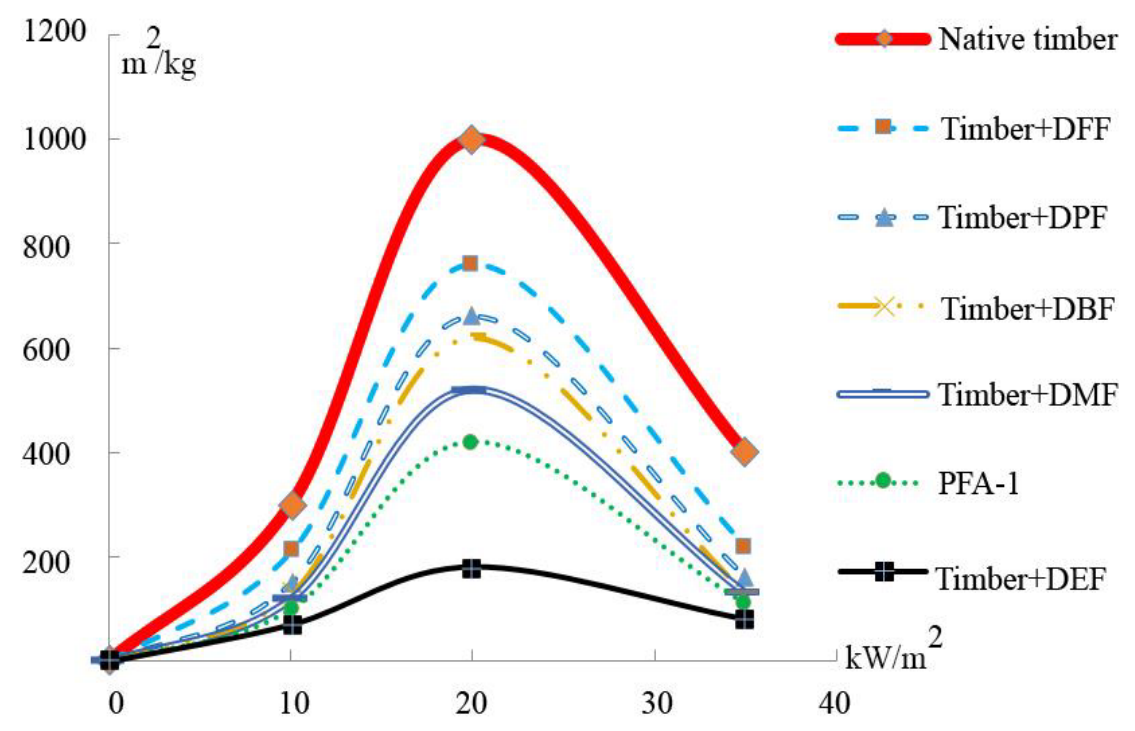

Fig. 1. Smoke-generation ability of timber modified by phosphorus compositions impregnated into timber surface

To clarify mechanism of modifiers action, phosphorus content was measured in the modified timber samples. Chemical composition was defined using scanning Quanta 200 microscope with appliance for elements analysis Apollo 40, using energy dispersive spectroscopy method. For the analysis, a surface layer of impregnated timber of $1 \mathrm{~mm}$ thick was cut off with scalpel. On the basis of data obtained as a result of chemical analysis of timber samples impregnated with phosphorus-containing modifiers (Table 1), it can be seen that DEF has the highest reactivity in interaction with timber.

Table 1. Content of phosphorus in the surface layer $(1 \mathrm{~mm})$ of the impregnated timber.

\begin{tabular}{|c|c|c|c|c|c|c|}
\hline Modifier & DMF & DEF & DPF & DBF & DFF & PFA-1 \\
\hline P, \% & 2.87 & 3.57 & 2.6 & 2.65 & 2.45 & 2.11 \\
\hline
\end{tabular}

A process of timber chemical modification with ethers of phosphorous acids can be described in the following way (Fig.2): 


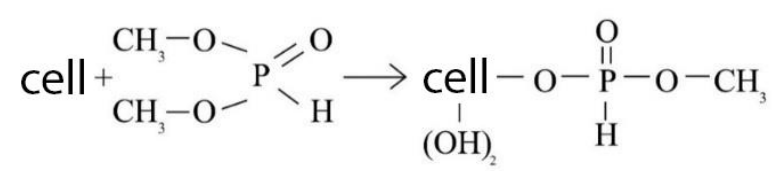

a<smiles>CCO[V](=O)O[Al](=O)OP(=O)(OCC)OCC</smiles>

b<smiles>CCCO[V](=O)O[IH2+2]OP(=O)(OCCC)OCCC</smiles><smiles>CCCCOP(=O)(OCCCC)O[V](=O)(O)OCCCC</smiles>

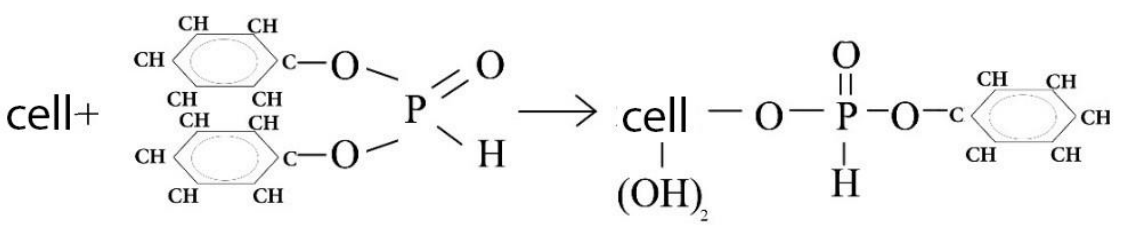

Fig. 2. Schemes of cellulose phosphorylation with use of DMF (a), DEF (b), DPF (c), DBF (d), DFF (e).

To clarify stability of the compositions formed as a result of impregnation, chemical analysis of surface layer of carbonaceous samples was carried out for impregnated timber (Table 2).

Table 2. Phosphorus content in the surface carbonaceous layer of impregnated timber.

\begin{tabular}{|c|c|c|c|c|c|c|}
\hline Modifier & DMF & DEF & DPF & DBF & DFF & PFA-1 \\
\hline P, \% & 0.85 & 4.7 & 0.63 & 0.71 & 1.06 & 0.35 \\
\hline
\end{tabular}

It can be seen from analysis of the obtained data, that the largest content of phosphorus is found out in timber modified with DEF, and this means that compositions formed as a result of timber modification with this composition has high stability.

It is known that smoke formation is a result of solid carbonaceous particles diffusion from the surface of timber. It is apparent that use of diethylphosphite as a modifier interferes diffusion of solid carbonaceous particles into atmosphere due to formation of stable chemical bonds.

Assessment of surface layer modifiers efficiency for construction timber requires definition of the main fire hazard indicators stipulated by state standards of the Russian Federation. Fire retardants implementation and further application at fire protection facilities becomes expedient if, as a result of tests performed in accordance with reference techniques, required fire protection efficiency is confirmed and reduction of construction timber fire hazard is reached. Main fire specifications are: combustibility, velocity of surface flame propagation, smoke-generation ability, toxicity of combustion gases. 
To define combustibility in the presence of the developed impregnation compositions, tests with use of method of slow-burning substances and materials group definition described in Interstate Standard 12.1.044 were carried out. Phosphorus compositions efficiently reacting with surface layer of timber were taken as modifiers.

Table 3. Test results for timber in presence of phosphorus impregnation compositions using of method of slow-burning substances and materials group definition.

\begin{tabular}{|c|c|c|c|c|}
\hline Sample & $\begin{array}{c}\Delta \mathrm{t}_{\max }, \\
\mathrm{C}\end{array}$ & $\tau_{\max }, \mathrm{c}$ & $\Delta \mathrm{m}, \%$ & $\begin{array}{c}\text { Burning index and combustibility } \\
\text { index }\end{array}$ \\
\hline Timber & 500 & 150 & 10.2 & $\begin{array}{c}\text { Combustible, medium } \\
\text { combustibility }\end{array}$ \\
\hline Timber + DMF & 200 & 280 & 4.8 & Combustible, inflammable \\
\hline Timber + DEF & 220 & 280 & 5.2 & Combustible, inflammable \\
\hline Timber + PFA-1 & 230 & 270 & 6.3 & Combustible, inflammable \\
\hline Timber + DFF & 220 & 200 & 7.1 & Combustible, inflammable \\
\hline
\end{tabular}

During the tests, following parameters were recorded: variation of temperature $\Delta$ tmax for light gaseous products produced at timber combustion, time $\tau$ max to maximal temperature of the timber combustion gases. Results are given in Table 3.

The results obtained show that when using inorganic phosphorus compositions ammonia polyphosphates and organic phosphorus compositions - protective effect is reached. Parameter $\Delta$ tmax for timber in the presence of DMF and DEF compositions is 2.5 times lower, than that for native timber. Amount of temperature increase during tests indicates intensity of timber thermodecomposition reactions and, therefore, ability of the fire protection facility to reduce intensity of these reactions. The indicator $\tau$ max indicates duration of this protective effect in time. For DMF and DEF this parameter is twice higher than for native timber.

To define group of fireproof effectiveness, tests were carried out in accordance with Interstate Standard 53292-2009. On the basis of results obtained (Table 4) it can be noted that loss of mass for sample of timber modified with DMF is reduced by 11 times, for DEF and PFA-1 - by 9 times.

Table 4. Results of tests on definition of fireproof efficiency group for fireproof composition.

\begin{tabular}{|c|c|c|}
\hline Sample & Mass loss, \% & $\begin{array}{c}\text { Group of fireproof } \\
\text { efficiency }\end{array}$ \\
\hline Native timber & 79.0 & III \\
\hline Timber, modified with DMF & 6.9 & I \\
\hline Timber, modified with DEF & 8.5 & II \\
\hline Timber, modified with DFF & 9.5 & I \\
\hline Timber, modified with PFA-1 & 8.7 & \\
\hline
\end{tabular}

Study of flame propagation process along the timber surface for timber with fireproof coverings was carried out using method described in Interstate Standard 12.1.044-89. During the tests the following parameters were considered: time of passing by the flame front of specified sample areas, maximal temperature of exhaust gases, maximum sample longwise damage caused by flame, time to maximal temperature of exhaust gases. On the basis of the data obtained the flame propagation index $I_{R P}$ - classification parameter - was calculated.

Study was carried out for following phosphorus-containing modifiers: DMF, DEF, DFF, PFA-1. Results of test on flame propagation along the surface of timber construction 
elements impregnated with fireproof compositions are given in Table 5. These results show that described timber treatment considerably reduces its ability to spread flame along the timber surface. All studied ethers of phosphorus acids considerably reduce parameter $I_{R P}$ (by 12-26 times). The best parameters were found out for timber modified with DMF and DEF.

Table 5. Flame propagation along the timber surface in the presence of phosphorus-containing modifiers.

\begin{tabular}{|c|c|c|c|c|c|c|}
\hline \multirow[b]{2}{*}{ № } & \multirow[b]{2}{*}{ Sample } & \multicolumn{2}{|c|}{$\begin{array}{l}\text { Time of flame passing } \\
\text { initial area }(30 \mathrm{~mm})\end{array}$} & \multirow{2}{*}{$\begin{array}{l}\text { Increase of } \\
\text { combustion } \\
\text { products } \\
\text { temperature, } \\
\text { C }\end{array}$} & \multirow{2}{*}{$\begin{array}{c}\text { Sample } \\
\text { longwise } \\
\text { damage, } \\
\mathrm{mm}\end{array}$} & \multirow{2}{*}{$\begin{array}{c}\text { Flame } \\
\text { propagation } \\
\text { parameter, } \\
\mathrm{I}_{\mathrm{FP}}\end{array}$} \\
\hline & & $\begin{array}{c}\text { Time }(\tau), \\
\mathrm{s}\end{array}$ & $\begin{array}{c}\text { Velocity } \\
\left(\mathrm{V}_{\mathrm{FP}}\right), \\
\mathrm{mm} / \mathrm{s}\end{array}$ & & & \\
\hline 1 & Native timber & 8 & 3.125 & 40 & 300 & 60 \\
\hline 3 & Timber+DMF & 240 & 0.12 & 15 & 50 & 2.3 \\
\hline 4 & Timber+DEF & 230 & 0.13 & 22 & 60 & 3.7 \\
\hline 5 & Timber+DFF & 200 & 0.15 & 25 & 80 & 4.7 \\
\hline 6 & Timber+PFA-1 & 210 & 0.14 & 21 & 65 & 3.9 \\
\hline
\end{tabular}

The following can be concluded on the basis of the study. The problem on fumigation at construction timber burning can be solved by development of chemical compositions efficiently reacting with the surface layer of the timber so that diffusion of solid carbonaceous particles from the timber surface into atmosphere decreases. For such compositions development, it is recommended to use ethers of phosphorus acids, in particular, diethylphosphite which considerably decreases smoke-generation ability (by 5-6 times), and also considerably reduces fire hazard of timber and this is of great importance for development of fireproof compositions for construction materials.

\section{References}

1. D. Bobacz. Behavior of Wood in Case of Fire (2008)

2. E.N. Pokrovskaya, Chemical-physical basis of tread life wood: monograph (2009)

3. D. A. Korolchenko, A. M. Lukyanov, World of Transport 4, 158 (2012)

4. A.N. Baratov, V.L.Pchelintsev, Fire safety (1997)

5. E.G. Butcher, A.C., Parnell Smoke control in fire safety design (1979)

6. R.M. Aseeva, B.B. Serkov, A.B. Sivenkov, The burning of wood and its flammable properties, monograph (2010)

7. R.M. Aseeva, G.E. Zaikov, The combustion of polymeric materials (1981)

8. V.A. Ushkov, D.I. Nevzorov, A.V. Kopytin, V.M. Lalayan, Fire and Explosion Safety 7, 27-35 (2014)

9. C.J.Young, J. Moss, J. Clin Anesth 1, 377-386 (1989)

10. D.J. Shusterman, Occup Med. 8, 469-503 (1993)

11. J. L. Bryan, J. A. Milke, Project People II. Final Report Health Care Report (1981)

12. Taubkin S.I., RSFSR Publ. 1, 230 (1944)

13. Polandov Yu.Kh., Dobrikov S.A., Korolchenko A.Ya., Fire and Explosion Safety 25, 17-26 (2016)

14. G.G.Orlov, D.A. Korolchenko, Fire and Explosion Safety 24, 62-67 (2015)

15. D.A. Korolchenko, A.F. Sharovarnikov, A.V. Byakov, Advanced Materials Research 1073-1076, 2353-2357 (2015)

16. D.A. Korolchenko, A.F. Sharovarnikov, Advanced Materials Research 1070-1072, 1794-1798 (2015) 
17. A.A. Kobelev, Development of complex fire and moisture resistant structure based on connections for surface modification of wood (Cand. tech. sci. diss, 2012)

18. U.L. Makovskiy, Fire protection of wood materials by phosphorous acid esters (1992) 